III ENEI

Encontro Nacional de

Economia Industrial e Inovação
Indústria e Desenvolvimento Econômico:

desafios e perspectivas

18 a 20 de setembro de 2018

Uberlândia - Minas Gerais

\title{
COMPETITIVIDADE INTERNACIONAL, TAXA DE CÂMBIO E COMÉRCIO PAULISTA DE VEÍCULOS AÉREOS: 1997-2016
}

\author{
Patrick Leite Santos ${ }^{1}$ \\ Luís Abel da Silva Filho ${ }^{2}$
}

Resumo: Este artigo tem como objetivo investigar a competitividade do setor de veículos aéreos do Estado de São Paulo no período de 1997 a 2016; e, como a taxa de câmbio impactou nas relações comerciais. Para tanto, são construídos três índices e realizados dois testes econométricos aplicados à séries temporais: o Índice de Vantagens Relativas nas Exportações (IVRE), o Índice de Competitividade Revelada (ICRV), o Índice de Orientação Regional (IOR); e, os testes de Cointegração de Johansen e o de Causalidade de Granger. Os resultados mostram indícios de que o setor conseguiu se estabelecer no mercado mundial com vantagens nos $I V R E$ e ICRV, tendo como principal parceiro, verificado a partir do $I O R$, a União Europeia (UE). No que se refere à taxa de câmbio, os testes mostraram que não existe relação de longo prazo entre as exportações de veículos aéreos e a taxa de câmbio real efetiva.

Palavras-chave: Veículos Aéreos; Competitividade; São Paulo.

Abstract: This article aims to investigate the competitiveness of the air vehicle sector of the State of São Paulo from 1997 to 2016; and how the exchange rate has impacted business relationships. In order to do so, three indices were constructed and two econometric tests were applied to the time series: the Index of Relative Advantages in Exports (IVRE), the Revealed Competitiveness Index (ICRV), the Regional Guidance Index (IOR); and, the Johansen Cointegration tests and the Granger Causation test. The results show evidence that the industry was able to establish itself in the world market with advantages in IVRE and ICRV, having as main partner, verified from the IOR, the European Union (EU). Regarding the exchange rate, the tests showed that there is no long-term relationship between the exports of air vehicles and the effective real exchange rate.

Keywords: Air Vehicles; Competitiveness; Sao Paulo.

Área ABEIN: 2.2 - Comércio internacional e cadeias de valor

Classificação JEL: F13, F14

\section{Introdução}

O mercado de aeronaves é caracterizado por ser um setor de alto valor agregado (Responsável por 8,7\% das exportações totais do Estado de São Paulo em 2016), extremamente dinâmico e de alta tecnologia e competitividade. É dividido em dois segmentos: civil e militar. Caracteriza-se pela alta competição entre as empresas participantes, devido à heterogeneidade dos produtos, pequena demanda, e altas barreiras à entrada.

\footnotetext{
${ }^{1}$ Instituto de Economia e Relações Internacionais da Universidade Federal de Uberlândia - IERI/UFU.

${ }^{2}$ Departamento de Economia da Universidade Regional do Cariri - URCA.
} 
Atrelado a isso, está à característica de produtos que envolvem alta tecnologia, que é o fator tempo, tanto para desenvolvimento quanto para resposta do mercado, além da rápida desatualização do produto (BASTOS, 2006).

As empresas deste mercado estão localizadas em regiões com alto grau de desenvolvimento, necessário à construção de encadeamento à produção, quanto a fornecedores de peças e equipamentos sofisticados, próximo a centros de formação intelectual, como universidades e centros de pesquisas, fatores cruciais para o sucesso na produção e na competitividade de setores com elevada intensidade tecnológica. Caracteriza-se pela pequena quantidade de empresas participantes, tanto como compradoras quanto fornecedoras (oligopsônio e oligopólio). Consequência do alto custo para produção (elevadas barreiras à entrada), devido às estruturas específicas, que não podem ser migradas para outros setores; e, o alto custo das aeronaves, que implica numa demanda muito restrita, basicamente empresas de serviços aéreos e governos (BERNARDES \& PINHO, 2002). No Brasil, a região com maior expressão nesse setor é o Sudeste, destacando-se o Estado de São Paulo (Responsável, em 2016, por 90,34\% das exportações brasileiras do setor). A principal empresa aérea do Brasil está localizada neste Estado, a Empresa Brasileira de Aeronáutica S.A. - Embraer (FORJAZ, 2005).

O mercado consumidor desse setor é, em grande parte, internacional, o que pode implicar no fato de que variáveis macroeconômicas possam ser determinantes cruciais para o seu nível de competitividade. Entre estas variáveis, uma das principais é a taxa de câmbio, determinada no Brasil, desde 1999, pela livre flutuação do mercado (MOLLO \& SILVA, 2016). A taxa de câmbio pode depreciar ou apreciar, conforme a preferência pela moeda nacional. Essa variação impacta direta e indiretamente no preço do produto exportado, tanto no valor final, quanto no custo de produção, pois além de ser exportado, boa parte de seus componentes são importados.

Dessa forma, o objetivo deste estudo é saber qual o nível de competitividade da indústria de aeronaves brasileiras localizadas em São Paulo. Em seguida, busca-se investigar se a variável independente - taxa de câmbio - regida pelo governo e pelo mercado, da qual os gestores das empresas do setor não possuem influência, tem impacto nas exportações do setor no período em apreço.

Dessa forma, o trabalho foi desenvolvido em cinco partes, onde: Além desta introdução, a segunda seção contempla uma breve revisão da literatura; em seguida, serão apresentados os procedimentos metodológicos adotados; na quarta seção, apresentam-se os resultados e discussões; e por último, na quinta seção, tecem-se as considerações finais.

\section{Competitividade internacional e o setor de veículos aéreos}

\subsection{Competitividade internacional}

Ao se tratar de competitividade internacional, centrado em exportações e importações, muitas podem ser as abordagens. Aqui a competitividade é tratada no âmbito da capacidade de elevar o quantum exportado pelo país. Assim, a análise centra-se a partir de duas óticas: primeiro, das vantagens comparativas; segundo, do impacto da taxa de câmbio sobre as exportações/importações do país no setor em apreço.

A primeira abordagem a ser tratada, (o estudo das vantagens comparativas) foi inserido na literatura econômica por David Ricardo em 1817, quando formulou uma teoria que trata do comércio internacional. Ricardo defende que uma região deveria se especializar na produção de produtos para os quais apresentasse vantagens comparativas em relação a outras regiões. Estas vantagens poderiam advir de diversos fatores, como terras abundantes, 
clima favorável, entre outros, que reduziriam o custo de produção mantendo o nível de qualidade; e, consequentemente, aumentaria o nível de competitividade na produção daquele item e garantiria vantagens nas relações de trocas com outras nações.

A taxa de câmbio é discutida como um fator de competitividade ao se entender que sua oscilação altera o preço do produto, sem que haja mudança nos preços dos fatores, necessariamente. Quando o câmbio deprecia o preço do produto nacional caí, pois é possível comprar mais unidades de real com uma unidade de dólar, e quando o câmbio aprecia, o preço do produto nacional aumenta, pois ocorre o inverso, uma unidade de dólar é capaz de comprar menos unidades de real. $\mathrm{O}$ seu valor pode ser definido de diversas formas, de acordo com o regime cambial adotado pelo país. Seus vários formatos se originam de três tipos básicos: flexível, quando é determinado pela dinâmica entre a oferta e a demanda por moeda estrangeira; administrado, quando o governo define bandas cambiais dentro das quais o preço da moeda poderá variar; e o fixo, no qual o valor é determinado pelo governo e não apresenta, portanto, oscilações (CUSHMAN \& DE VITA, 2017).

Gráfico 1: Evolução da taxa de câmbio: 1997-2016.

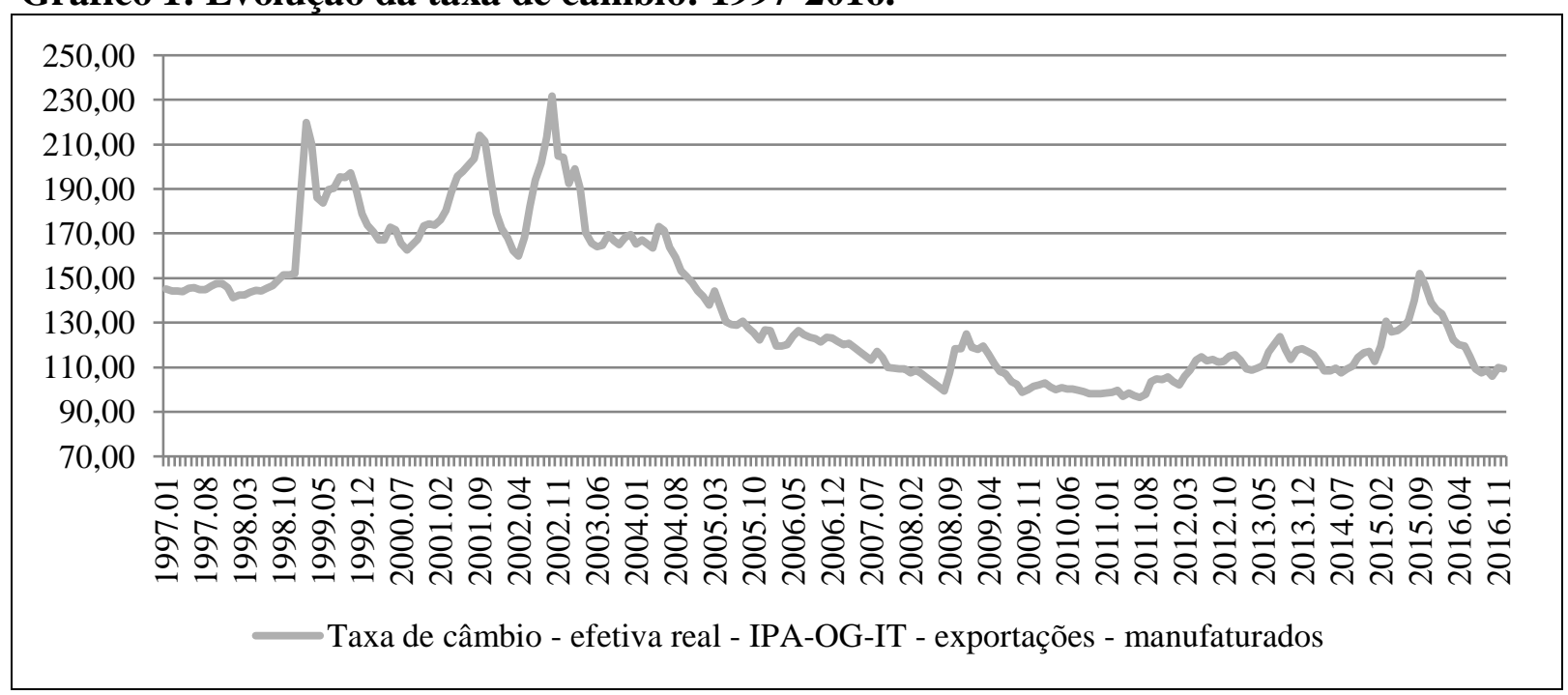

Fonte: Elaborado pelos autores a partir de dados do IPEADATA, 2017.

No Brasil, o regime cambial foi alterado em 1999 de fixo para flutuante (MOLLO \& SILVA, 2016). O gráfico 1 mostra a evolução da taxa de câmbio efetiva real utilizada para as exportações de manufaturados no período de 1997- 2016, tendo $2010=100$. Observa-se que a taxa oscila entre 232,00 e 90,00, estando na maior parte da série depreciada.

O período de maior volatilidade e depreciação ocorreu logo após a flexibilização do câmbio, em 1999. A alta volatilidade dura até meados de 2003, quando se estabilizou e entrou em uma tendência de queda de longo prazo ou apreciação cambial.

\subsection{Considerações sobre a indústria de veículos aéreos brasileiros e paulistas}

Atualmente, a Embraer está entre as quatro principais empresas produtoras de aeronaves do mundo, junto da Boeing, Airbus e Bombardier. Esta última é canadense e concorrente direta da Embraer na produção de jatos de médio e pequeno porte, enquanto as outras duas disputam o mercado das aeronaves de grande porte (FORJAZ, 2005). A empresa conta com aproximadamente 19 mil funcionários, e possui capital cotado nas Bolsas de Valores do Brasil e de Nova York, com valor aproximado de $\mathrm{R} \$ 20,4$ bilhões, a preços de março de 2013 (MANINI \& CALDAS, 2017). 
A relação comercial de exportação e importação de veículos aéreos brasileiros é caracterizada pela importação de insumos, que vão desde tecnologia em softwares até partes físicas, como metais especiais. Por se tratar de uma dinâmica onde as empresas brasileiras adicionam valor ao produto e vendem esse no mercado internacional, sobretudo, espera-se que a relação seja superavitária, e isto realmente ocorre (FORJAZ, 2005).

A tabela 1 apresenta as relações comerciais de veículos aéreos do Brasil, exportações, importações e saldo da balança comercial, no período de 1997 a 2016. Observa-se que as exportações brasileiras de aeronaves seguem tendência de crescimento, aumentando de forma significativa durante o período em análise. Já as importações, apresentam tendência de queda até o ano de 2003, de 2004 em diante passam a apresentar resultados crescentes, e retornam à tendência de queda a partir de 2014. Tem-se que as variações das exportações e importações não são constantes, o que indica a não existência de um padrão pré-determinado. Essa característica é peculiar a nichos que comercializam seu produto por meio de contratos, ocorrendo de obter demandas e rendas sem periodicidade (BASTOS, 2006).

Tabela 1: relações comerciais brasileiras de aeronaves: exportações, importações e saldo da balança comercial, 1997-2016.

\begin{tabular}{cccccccccc}
\hline Ano & Exportação - US\$ & Var. \% & Importação - US\$ & Var. \% & Saldo & Var. \% \\
\hline 1997 & 681.026 .786 & 0,00 & 636.411 .030 & 0,00 & 44.615 .756 & 0,00 \\
1998 & 1.169 .983 .998 & 71,80 & 572.361 .229 & $-10,06$ & 597.622 .769 & $1.239,49$ \\
1999 & 1.784 .801 .867 & 52,55 & 399.743 .921 & $-30,16$ & 1.385 .057 .946 & 131,76 \\
2000 & 3.446 .951 .845 & 93,13 & 427.777 .145 & 7,01 & 3.019 .174 .700 & 117,98 \\
2001 & 3.372 .471 .699 & $-2,16$ & 86.212 .678 & $-79,85$ & 3.286 .259 .021 & 8,85 \\
2002 & 2.714 .584 .853 & $-19,51$ & 130.631 .302 & 51,52 & 2.583 .953 .551 & $-21,37$ \\
2003 & 1.974 .789 .096 & $-27,25$ & 80.817 .488 & $-38,13$ & 1.893 .971 .608 & $-26,70$ \\
2004 & 3.285 .766 .524 & 66,39 & 94.417 .904 & 16,83 & 3.191 .348 .620 & 68,50 \\
2005 & 3.185 .533 .539 & $-3,05$ & 131.447 .284 & 39,22 & 3.054 .086 .255 & $-4,30$ \\
2006 & 3.263 .119 .339 & 2,44 & 219.018 .926 & 66,62 & 3.044 .100 .413 & $-0,33$ \\
2007 & 4.772 .851 .114 & 46,27 & 598.763 .340 & 173,38 & 4.174 .087 .774 & 37,12 \\
2008 & 5.498 .453 .587 & 15,20 & 1.264 .603 .859 & 111,20 & 4.233 .849 .728 & 1,43 \\
2009 & 3.870 .790 .885 & $-29,60$ & 989.991 .680 & $-21,72$ & 2.880 .799 .205 & $-31,96$ \\
2010 & 3.999 .051 .023 & 3,31 & 1.082 .149 .009 & 9,31 & 2.916 .902 .014 & 1,25 \\
2011 & 3.939 .536 .552 & $-1,49$ & 1.130 .146 .545 & 4,44 & 2.809 .390 .007 & $-3,69$ \\
2012 & 4.759 .182 .662 & 20,81 & 1.435 .491 .453 & 27,02 & 3.323 .691 .209 & 18,31 \\
2013 & 3.841 .711 .881 & $-19,28$ & 1.525 .367 .198 & 6,26 & 2.316 .344 .683 & $-30,31$ \\
2014 & 3.440 .335 .845 & $-10,45$ & 1.267 .159 .791 & $-16,93$ & 2.224 .283 .118 & $-3,97$ \\
2015 & 4.088 .191 .801 & 18,83 & 1.088 .152 .319 & $-14,13$ & 3.000 .039 .482 & 34,88 \\
2016 & 4.430 .585 .661 & 8,38 & 350.554 .580 & $-67,78$ & 4.080 .031 .081 & 36,00 \\
\hline
\end{tabular}

Fonte: Elaborado pelos autores a partir de dados da SECEX/ MDIC, 2017.

A tendência de crescimento das exportações é descontinuada em períodos que ocorreram grandes catástrofes a nível mundial, como em 2001 e nos anos sequentes, até 2003, devido ao atentado terrorista ao World Trade Center nos EUA, em 11 de setembro de 2001, que afetou de forma especial o mercado de transportes aéreos, prejudicando consequentemente toda a cadeia de produção de aeronaves e suprimentos para esse setor; e, em 2009, após a crise financeira que se iniciou nos Estados Unidos, no ano de 2008, e se espalhou pelo mercado mundial (Sub-prime). Após atingir em 2000 a maior variação positiva do período, 93,1\%, o agregado de exportações fecha o ano de 2001 com uma variação negativa de 2,2\%, que é prolongada até 2003 quando atinge a segunda maior variação negativa do período analisado, $27,3 \%$.

Morais et al. (2016) explicou que a estratégia recente tem sido a de internacionalização, onde as empresas tentam se expandir para outros países em busca de vantagens comparativas e de novos mercados consumidores. No caso da Embraer, tem-se recentemente ocorrido um processo de inserção no mercado Chinês, por meio do modelo de 


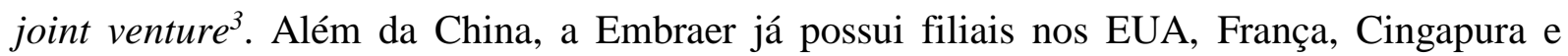
Portugal (MANINI \& CALDAS, 2017).

As importações são menos sensíveis às crises devido a serem realizadas de acordo com a demanda dos contratos firmados, característica do mercado, que trabalha sob encomenda e não mantêm estoque de insumos. Formato de produção desenvolvido pela fabricante japonesa Toyota, e que ficou conhecido como Sistema Toyota de Produção (STP $)^{4}$. Esse formato de produção é atualmente o predominante em diversos setores, principalmente aqueles que trabalham via encomendas e contratos (GHINATO, 1996). Ainda assim, as importações se mostram sensíveis aos fatos de caráter macroeconômico, reflexo da retração da demanda, que pode ser observada nitidamente nos anos de 2001 e 2009, anos em que ocorreram perturbações macroeconômicas em níveis mundiais e impactaram fortemente sobre o setor.

Tabela 2: relações comerciais paulistas de aeronaves: exportações, importações e saldo da balança comercial, 1997-2016.

\begin{tabular}{c|c|c|c|c|c|c}
\hline Ano & Exportação - US\$ & Var. \% & Importação - US\$ & Var. \% & Saldo & Var. \% \\
\hline 1997 & 586.859 .612 & 0,00 & 249.716 .032 & 0,00 & 337.143 .580 & 0,00 \\
1998 & 1.090 .626 .849 & 85,84 & 457.470 .063 & 83,20 & 633.156 .786 & 87,80 \\
1999 & 1.579 .820 .136 & 44,85 & 319.756 .661 & $-30,10$ & 1.260 .063 .475 & 99,01 \\
2000 & 2.591 .757 .890 & 64,05 & 279.543 .178 & $-12,58$ & 2.312 .214 .712 & 83,50 \\
2001 & 2.762 .842 .232 & 6,60 & 23.416 .078 & $-91,62$ & 2.739 .426 .154 & 18,48 \\
2002 & 2.321 .936 .921 & $-15,96$ & 13.640 .301 & $-41,75$ & 2.308 .296 .620 & $-15,74$ \\
2003 & 1.923 .187 .182 & $-17,17$ & 12.654 .643 & $-7,23$ & 1.910 .532 .539 & $-17,23$ \\
2004 & 3.229 .017 .097 & 67,90 & 48.261 .074 & 281,37 & 3.180 .756 .023 & 66,49 \\
2005 & 3.152 .487 .968 & $-2,37$ & 16.817 .881 & $-65,15$ & 3.135 .670 .087 & $-1,42$ \\
2006 & 3.158 .616 .189 & 0,19 & 27.492 .355 & 63,47 & 3.131 .123 .834 & $-0,14$ \\
2007 & 4.517 .897 .722 & 43,03 & 93.158 .955 & 238,85 & 4.424 .738 .767 & 41,31 \\
2008 & 5.466 .616 .445 & 21,00 & 539.443 .079 & 479,06 & 4.927 .173 .366 & 11,36 \\
2009 & 3.860 .758 .516 & $-29,38$ & 248.735 .358 & $-53,89$ & 3.612 .023 .158 & $-26,69$ \\
2010 & 3.950 .926 .544 & 2,34 & 193.984 .784 & $-22,01$ & 3.756 .941 .760 & 4,01 \\
2011 & 3.922 .890 .443 & $-0,71$ & 208.445 .595 & 7,45 & 3.714 .444 .848 & $-1,13$ \\
2012 & 4.562 .175 .554 & 16,30 & 252.913 .767 & 21,33 & 4.309 .261 .787 & 16,01 \\
2013 & 3.775 .327 .380 & $-17,25$ & 152.893 .958 & $-39,55$ & 3.622 .433 .422 & $-15,94$ \\
2014 & 3.406 .050 .836 & $-9,78$ & 189.837 .994 & 24,16 & 3.216 .212 .842 & $-11,21$ \\
2015 & 3.681 .139 .880 & 8,08 & 133.420 .343 & $-29,72$ & 3.547 .719 .537 & 10,31 \\
2016 & 4.002 .545 .485 & 8,73 & 146.469 .453 & 9,78 & 3.856 .076 .032 & 8,69 \\
\hline
\end{tabular}

Fonte: Elaborado pelos autores a partir de dados da SECEX/ MDIC, 2017.

A tabela 2 mostra as relações comerciais de São Paulo no mesmo período. Este, assim como o Brasil, é afetado diretamente no volume comercializado em decorrência de eventos de caráter macroeconômico. Ademais, por ser o maior centro financeiro e econômico do país, os efeitos de eventos macroeconômicos em níveis mundiais afetam as principais economias do mundo e os estados economicamente mais desenvolvidos, a exemplo de São Paulo, também são os principais afetados, inicialmente. Posteriormente, os efeitos se espalham por todos os estados do país.

Comparando-se a tabela 2 com a tabela 1, tem-se que o Estado de São Paulo é responsável por parte significativa das relações comerciais brasileiras de aeronaves. As

\footnotetext{
${ }^{3}$ Joint venture é uma espécie de negócio em conjunto, onde duas ou mais empresas fazem um acordo para alcançar um objetivo comum. Tem sido muito utilizado em países como a China, onde as barreiras protecionistas são muito presentes (MORAIS et al, 2016).

${ }^{4}$ O Sistema Toyota de Produção (STP) vai muito além do formato de produção just in time (JIT) e Kanbam, como normalmente ficou conhecido. Esse sistema tem como preocupação maior o controle de perdas, tomando como pilares o JIT e a automação dos processos. Além desses, é interessante destacar o Controle de Qualidade Zero Defeitos (CQZD), que agregado aos demais, faz com que todo sistema funcione (GHINATO, 1996).
} 
exportações paulistas são responsáveis por aproximadamente $94,1 \%$ no período de 1997 a 2016. As importações são menos expressivas, representando $26,7 \%$ da totalidade importada pelo Brasil no mesmo período. O baixo valor das importações do estado de São Paulo, em relação ao importado pelos demais estados, levanta duas hipóteses, já que a maior parte da produção de aeronaves brasileiras está concentrada no estado de São Paulo:i) as importações das matérias-primas utilizadas no setor estão chegando por outros portos e aeroportos do país, para evitar maiores custos do que teria se chegasse pelo estado de São Paulo; ii)o volume importado pelos demais estados está sendo utilizado na manutenção da frota atual de aeronaves do país. Devido a essa disparidade, o saldo comercial de São Paulo no setor é mais elevado do que o do país.

O gráfico 2 mostra a participação relativa das exportações de veículos aéreos de São Paulo sobre as exportações totais de 1997 a 2016. Observa-se que ocorre significativo crescimento da participação relativa dos veículos aéreos na exportação total de São Paulo até o ano de 2001, quando a partir de então se tem queda e estabilização da participação em torno de $7 \%$.

Gráfico 2: São Paulo: 1997-2016: participação relativa das exportações de veículos aéreos sobre as exportações totais.

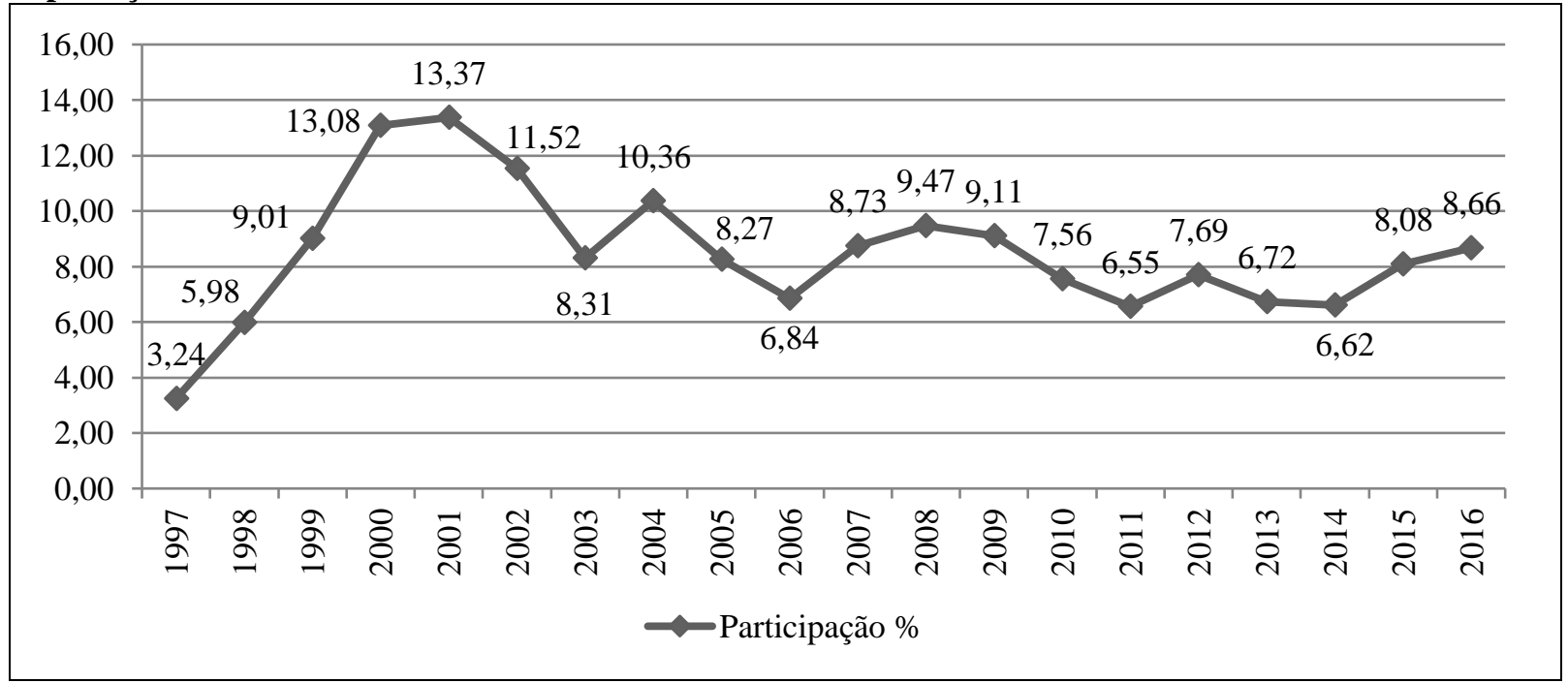

Fonte: Elaborado pelos autores a partir de dados da SECEX/ MDIC, 2017.

Analisando-se a série por inteira identifica-se que ocorreu elevação da participação do setor no período, que saiu de 3,2\%, em 1997, primeiro ano da série, para 8,7\%, em 2016, último ano da série. É pertinente apontar, que após 2001 e 2008, anos em que ocorreram eventos macroeconômicos negativos em nível mundial, houve queda da participação do setor, o que indica sua inter-relação às cadeias produtivas e aos mercados consumidores em nível mundial.

O gráfico 3 apresenta a participação relativa das importações de veículos aéreos de São Paulo sobre as importações totais de 1997 a 2016. Há anos de elevados registros de coeficientes de importação, mas com um comportamento da série relativamente estável em longos períodos, a exemplo de 2001-2007, 2010-2016.

Gráfico 3: São Paulo: 1997-2016: participação relativa das importações de veículos aéreos sobre as importações totais. 


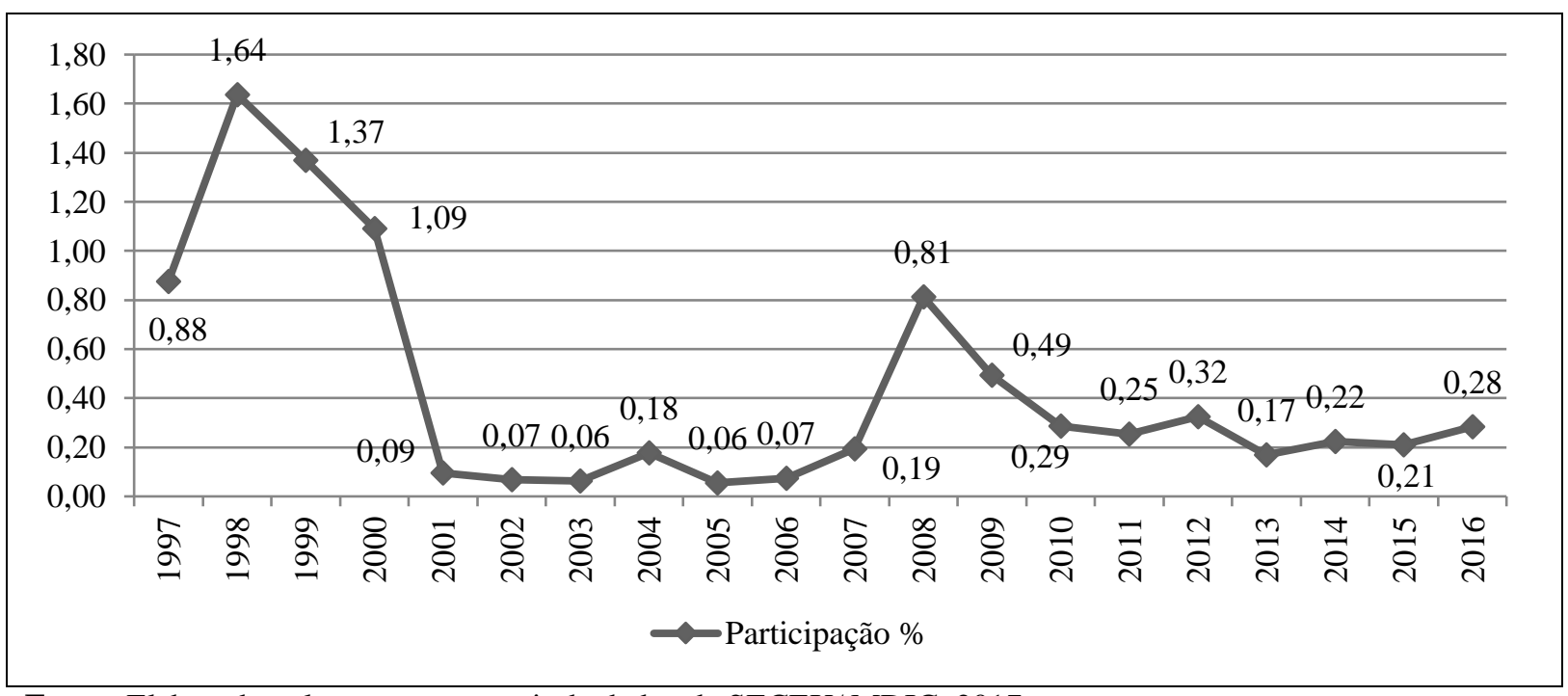

Fonte: Elaborado pelos autores a partir de dados da SECEX/ MDIC, 2017.

Ao contrário do que ocorreu no gráfico 2, partiu-se aqui de uma elevada participação nas importações totais, e posteriormente, a partir de 2001, tem-se queda da participação, com estabilização em torno de 0,20\%. Destaque-se, que, assim como ocorreu na participação das exportações, a dinâmica das importações também foi impactada quando da ocorrência de crises em nível macroeconômico mundial, como pode ser observado pelas bruscas oscilações nos anos de 2001 e 2008.

\section{Metodologia}

Para cumprir os objetivos propostos, a metodologia foi dividida em duas partes. A primeira mostra o método de construção dos índices, utilizado para medir o nível de competitividade da indústria de aeronaves brasileira localizada em São Paulo, que foram construídos para as informações totais anuais. A segunda apresenta o método de testes, utilizado para verificar se a taxa de câmbio real efetiva tem impacto nas exportações do setor no período, construídos a partir de uma amostra mensal.

\section{1. Índices}

O Índice de Vantagem Relativa nas Exportações (IVRE), elaborado por Balassa (1965) e aprimorado por Vollrath (1989), mede a vantagem relativa nas exportações $X$ de uma determinada região $r$, em relação ao total do país $t$, de um produto $p$. Para tal, usa-se a expressão abaixo:

$$
I V R E_{p r}=L N\left[\frac{X_{p r}}{X_{p t}} / \frac{X_{j r}}{X_{j t}}\right]
$$

Onde, $X=$ Exportações; $p=$ Produto (Veículos aéreos); $r=$ Estado (São Paulo); $j=$ Agregado de todos os produtos, excluindo-se $p ; t=$ Todos os estados (Brasil), excluindo-se $r$ (São Paulo).

Para analisar os resultados tem-se que: Quando o $I V R E_{p r}=0$, o estado (São Paulo) não tem nem vantagem nem desvantagem em relação ao conjunto dos Estados (Brasil) na 
exportação do produto (veículos aéreos). Já quando o $I V R E_{p r}>0$, o Estado em análise possui vantagem na exportação do referido produto em relação ao restante dos Estados. E quando o $I V R E_{p r}<0$, significa que o Estado (São Paulo), não possui vantagem na exportação do produto em relação aos demais Estados.

O Índice de Competitividade Revelada (ICRV), também elaborado por Balassa (1965) e aprimorado por Vollrath (1989), segue o mesmo princípio do IVRE, adicionando, porém, as importações $M$ ao cálculo. Essa alteração torna o índice mais completo, pois leva em consideração todas as transações do produto realizados pelo país, estado ou região no período analisado. Assim, tem-se a expressão abaixo:

$$
I C R V_{p r}=L N\left[\left(\frac{X_{p r}}{X_{p t}} / \frac{X_{j r}}{X_{j t}}\right) /\left(\frac{M_{p r}}{M_{p t}} / \frac{M_{j r}}{M_{j t}}\right)\right]
$$

Onde, $M=$ Importações; $X=$ Exportações; $p=$ Produto (Veículos aéreos); $r=$ Estado (São Paulo); $j=$ Agregado de todos os produtos, excluindo-se $p ; t=$ Todos os estados (Brasil), excluindo-se $r$ (São Paulo).

Quanto à análise, tem-se que: Quando $I C R V_{p r}=0$, o Estado (São Paulo), possui competitividade igual ao restante das regiões do país na produção de veículos aéreos. Quando $I C R V_{p r}>0$, significa que o Estado de São Paulo possui competitividade maior que as demais regiões do país na produção de veículos aéreos. E quando $I C R V_{p r}<0$, tem-se que São Paulo possui competitividade abaixo do restante do país na produção de veículos aéreos.

O Índice de Orientação Regional (IOR), desenvolvido por Yeats (1997), permite quantificar a tendência de exportação de um país ou estado para determinados parceiros comerciais. Nesse estudo será utilizado para verificar o IOR das exportações paulistas para a União Europeia (UE). Para tanto, é utilizado como método de cálculo à equação (3) abaixo:

$I O R=\left[\frac{\left(X_{s a} / X_{s t}\right)}{\left(X_{f a} / X_{f t}\right)}\right]$

Onde, $X_{s a}=$ Exportações de Aeronaves de São Paulo para a UE; $X_{s t}=$ Exportações totais de São Paulo para a UE; $X_{f a}=$ Exportações de Aeronaves de São Paulo menos a UE; $X_{f t}=$ Exportações totais de São Paulo menos a UE.

Quanto à análise, tem-se que o IOR varia de 0 ao infinito: $0 \leq I O R \leq \infty$. Quanto maior o seu coeficiente, maior a tendência de São Paulo exportar Aeronaves para a UE (YEATS, 1997). Exemplos de aplicação dessa metodologia são encontrados nos trabalhos de Coronel et al (2008), Silva et al (2015).

\subsection{Teste de raiz unitária}

Neste artigo, segunda parte proposta para análise, confere a necessidade de se fazer uma análise aplicada com testes econométricos robustos e amplamente utilizados na literatura em questão. Assim, busca-se analisar os impactos da taxa de câmbio real efetiva sobre as exportações paulistas de veículos aéreos entre 1997-2016. As informações são mensais e contempla um número de 240 observações tanto para as exportações quanto para a taxa de câmbio.

Para o prosseguimento à análise, foi necessário a verificação do teste de estacionariedade das séries realizada por meio do argumento Dichey-Fuller Aumentado 
(ADF) e por meio do teste Elliot, Rothenberg \& Stock (ERS). estes testes tem o fito de verificar se as séries possuem ou não raiz unitária, diante de modelos em que as variáveis são geradas por processos Auto Regressivos de ordem $\rho$. Com os resultados dos testes, caso necessário, é possível realizar a inclusão da diferença na variável defasada para que se preserve a condição de ruído branco. Destarte, as séries devem possuir média zero e variância infinita. Ou seja, as séries devem apresentar comportamentos estáveis ao longo do tempo.

A realização do teste de raiz unitária foi feito a partir do uso do Software R, com o pacote urca, e usaram-se as equações matemáticas que as denominam, a saber:

$$
\begin{aligned}
& \Delta Y_{t}=\alpha+\beta t+\gamma Y_{t-1}+\sum_{i=1}^{p-1} \delta_{i} \Delta Y_{t-1}+\varepsilon_{t \prime} \\
& \Delta Y_{t}=\alpha+\gamma Y_{t-1}+\sum_{i=1}^{p-1} \delta_{i} \Delta Y_{t-1}+\varepsilon_{t \prime} \\
& \Delta Y_{t}=\gamma Y_{t-1}+\sum_{i=1}^{p-1} \delta_{i} \Delta Y_{t-1}+\varepsilon_{t \prime}
\end{aligned}
$$

As diferenças entre as três equações são dadas considerando-se apenas a ausência da tendência linear na segunda equação $\beta t$; e tendência linear $\beta t$ e do termo constante $\alpha$ na terceira equação. Assim, os testes foram desenvolvidos com os termos de tendência e constantes; somente com constantes; e, sem tendência e sem constantes, conforme a tabela 01 (seção 3), sendo a forma indicada para o alcance de resultados robustos.

A hipótese nula do teste: $H 0: \gamma$, é a existência de pelo menos uma raiz unitária. Com isso, rejeitar H0: $\gamma$ significa afirmar que a série é estacionária e, em si, já tem distribuição que são um ruído branco gaussiano. Nesse sentido, as equações são estimadas por Mínimos Quadrados Ordinários - MQO, e os valores dos parâmetros estimados são validados enquanto testes de raiz unitária, a partir da comparação aos valores críticos propostos e apresentados por Dichey-Fuller (1979; 1981) e também confirmados pelo teste indicado por Elliot, Rothenberg \& Stock (1996).

\subsection{Teste de cointegração de Johansen - Modelo multivariado}

De posse dos resultados dos testes de raiz unitária, se as variáveis mostrarem-se não estacionárias, recorre-se aos teste que permitam verificar se há relação de equilíbrio de longo prazo entre elas, a partir da aplicação da diferença. Com isso, analisar se há cointegração é o procedimento mais viável adotado para estes fins. Tendo como orientação os testes aplicados para modelagem VAR, recorre-se ao teste de cointegração de Johansen (1988). Nesse teste, Johansen (1988) propõe analisar se há presença de múltiplos vetores de cointegração ou não, quando se utiliza um modelo de Vetores Auto Regressivos, testando-se como mecanismos de correção de erro (VECM), representado da forma que se segue.

$$
\Delta X_{t}=\Phi X_{t-1}+\sum_{i=1}^{p-1} \Lambda_{i} \Delta X_{t-1}+\varepsilon_{t}
$$

Aqui, cada $X_{i}$ representa um vetor de variáveis endógenas em primeira diferença; aonde $\phi$ representa uma Matriz de dados expressa por $N x N$, e seu posto é representado por $r<N$, nos casos em que há cointegração entre as séries; lamba $\Lambda_{i}, i=1,2, \ldots, p-1$ são determinadas matrizes $N x N$ que contêm os coeficientes das variáveis endógenas defasadas 
em seus valores; e, $\varepsilon_{t} N x 1$ representa um vetor de erros ou perturbações aleatórias não correlacionados entre si, contemporânea ou temporalmente, sendo que a média é zero e a matriz de covariância apresenta valores de variância e covariância não singulares.

\subsection{Teste de Causalidade de Granger}

O segundo teste proposto neste estudo é o teste de causalidade de Granger. Ele é amplamente utilizado na literatura recente em econometria com séries temporais, dado sua aceitação universal, uma vez que este teste vai muito além da identificação de uma correlação simples entre as variáveis. No sentido de Granger, correlação pode não implicar em causalidade. Ou seja, pode não apresentar necessariamente uma relação de causa e efeito entre variáveis que são correlacionadas. Destarte, para Granger (1969), só é possível estabelecer uma relação de causa e efeito, se valores passados de $X_{t-1}$ ajudar a prever valores presentes de $Y_{t}$. Nesse sentido, é preciso uma relação de causalidade entre as séries que não podem ser denotadas apenas pela relação estatística de correlação.

Assim, considerando-se as séries de tempo $X_{t}$ e $Y_{t}^{2}$, as pressuposições assumidas pelo teste de Causalidade de Granger, são as de que: $i$ ) as séries de tempo $X_{t}$ e $Y_{t}^{2}$ contêm todas as informações relevantes para as predições de causa e efeito entre elas; $i i$ ) como resultado, a série de tempo estacionária $X_{t}$ Granger-causa outra série estacionária $Y_{t}^{2}$, se as predições, com níveis aceitáveis de significância estatística, puderem ser obtidas, incluindo-se valores defasados de $X_{t}$ aos valores defasados de $Y_{t}^{2}$.

As equações matemáticas que podem expressar essa relação de causa-efeito podem ser escritas da seguinte forma:

$$
\begin{aligned}
& X_{t}=\sum a_{i} Y_{t-i}+\sum b_{i} X_{t-i}+\mu_{1 t} \\
& Y_{t}=\sum c_{i} Y_{t-i}+\sum d_{i} X_{t-i}+\mu_{2 t}
\end{aligned}
$$

As duas equações representam relações de causalidade, no sentido de Granger, em que: $\boldsymbol{\mu}_{\boldsymbol{i}}$ contém os ruídos não correlacionados, em tese; na equação (8), assume-se que os valores correntes da variável $\boldsymbol{X}_{\boldsymbol{t}}$ estão relacionados aos valores passados do próprio $\boldsymbol{X}_{\boldsymbol{t}-1}$, bem como aos valores defasados de $\boldsymbol{Y}_{\boldsymbol{t}}$; e, a equação (9) representa comportamento semelhante para a variável $\boldsymbol{Y}_{\boldsymbol{t}}$, em que os valores correntes da variável $\boldsymbol{Y}_{\boldsymbol{t}}$ estão relacionados aos valores passados do próprio $\boldsymbol{Y}_{\boldsymbol{t}-1}$, bem como aos valores defasados de $\boldsymbol{X}_{\boldsymbol{t}}$. Assim, a causalidade de Granger pode ser observada para as séries no quadro 1.

Quadro 1: Variáveis de interesse dos modelos.

\begin{tabular}{|l|l|}
\hline \multicolumn{1}{|c|}{ Variável } & \multicolumn{1}{c|}{ Descrição } \\
\hline EXPORT & Exportações de aeronaves do Estado de São Paulo. \\
\hline TXCAMBIO & Taxa de câmbio - efetiva real - IPA-OG-IT - Exportações - manufaturados. \\
\hline DEXPORT & Primeira diferença da variável EXPORT. \\
\hline DTXCAMBIO & Primeira diferença da variável TXCAMBIO. \\
\hline
\end{tabular}

Fonte: Elaborado pelo autor a partir de dados da SECEX/ MDIC e do IPEADATA, 2017.

De acordo com a literatura, duas são as hipóteses esperadas:

1) Que a relação entre as exportações e a taxa de câmbio efetiva real seja negativa;

2) Que as alterações da taxa de câmbio efetiva real causem alterações nas exportações. 


\section{Resultados e Discussões}

\subsection{Competitividade paulista no comercio de veículos aéreos no mercado internacional: evidências empíricas}

Aplicada à primeira parte da metodologia proposta, chega-se aos resultados apresentados abaixo nos gráficos: 4, 5 e 6.0 primeiro, gráfico 4, mostra o índice de vantagem relativa nas exportações (IVRE) de veículos aéreos do Estado de São Paulo no período de 1997 a 2016. Observa-se que o Estado tem valores positivos para todos os anos da série em análise.

Gráfico 4: IVRE nas exportações paulistas de veículos aéreos, 1997-2016.

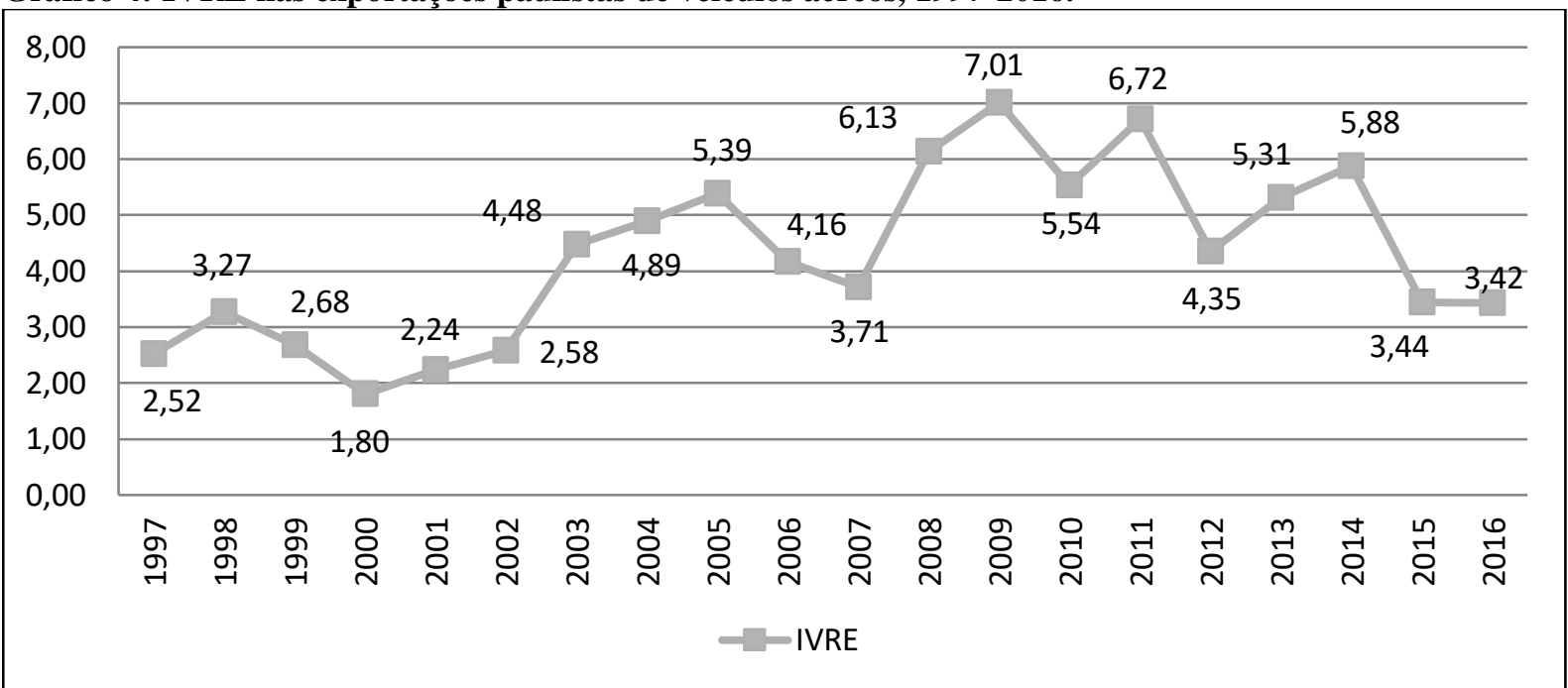

Fonte: Elaborado pelos autores a partir de dados da SECEX/ MDIC, 2017.

Os dados do IVRE apresentam tendência ao crescimento observado no longo prazo, porém, com movimentos cíclicos, quando desmembrado em períodos mais curtos, o que é característico de setores e economias desenvolvidas (KALECKI, 1983). Por se tratar de um setor globalizado, em que os principais consumidores finais estão no mercado externo, assim como os principais fornecedores de peças e tecnologia em softwares, os resultados são vulneráveis a ocorrências externas, como variações cambiais, catástrofes, ou dificuldades financeiras de países externos. Ocorrendo o fato de que alterações na dinâmica de uma região influencia no desempenho de outra (SCHUMPETER, 1982).

Os valores mais baixos são registrados nos primeiros anos da série, entre 1997 e 2002. Esse período é caracterizado por inúmeras turbulências no mercado mundial. Em 1997, a crise financeira assolou o mercado asiático, responsável por parte da demanda brasileira de aeronaves. Em 1998 estourou a crise financeira da Rússia, que também dificultou as transações internacionais. Em 1999 o Brasil sofreu com a crise de desvalorização do real, que tornou o cenário bom para as exportações, porém, ruim para importações, além de prejudicar o setor creditício, tão importante para o setor aéreo brasileiro. E, em 2001, ocorreu o atentado as Torres Gêmeas nos EUA. Mas, a partir de 2003 apresentou-se reversão significativa da tendência de queda para ascensão. Nesse período, o país passou por mudanças no cenário político.

Mas apesar dos distúrbios e turbulências ocorridos, e da queda observada nos últimos anos da série, estes não impediram a boa evolução do setor, que encerrou a série em análise com aumento de 0,9 pontos percentuais no IVRE, valor significativo para um setor de alta 
competitividade, oligopolizado e de empresas já estabelecidas no mercado de concorrência mundial.

O gráfico 5 apresenta os índices referentes a competitividade revelada do Estado de São Paulo na comercialização de veículos aéreos. É possível verificar a partir destes se os dados corroboram os encontrados no IVRE apresentado no gráfico 4.

Gráfico 5: ICRV paulista na comercialização de veículos aéreos, 1997-2016.

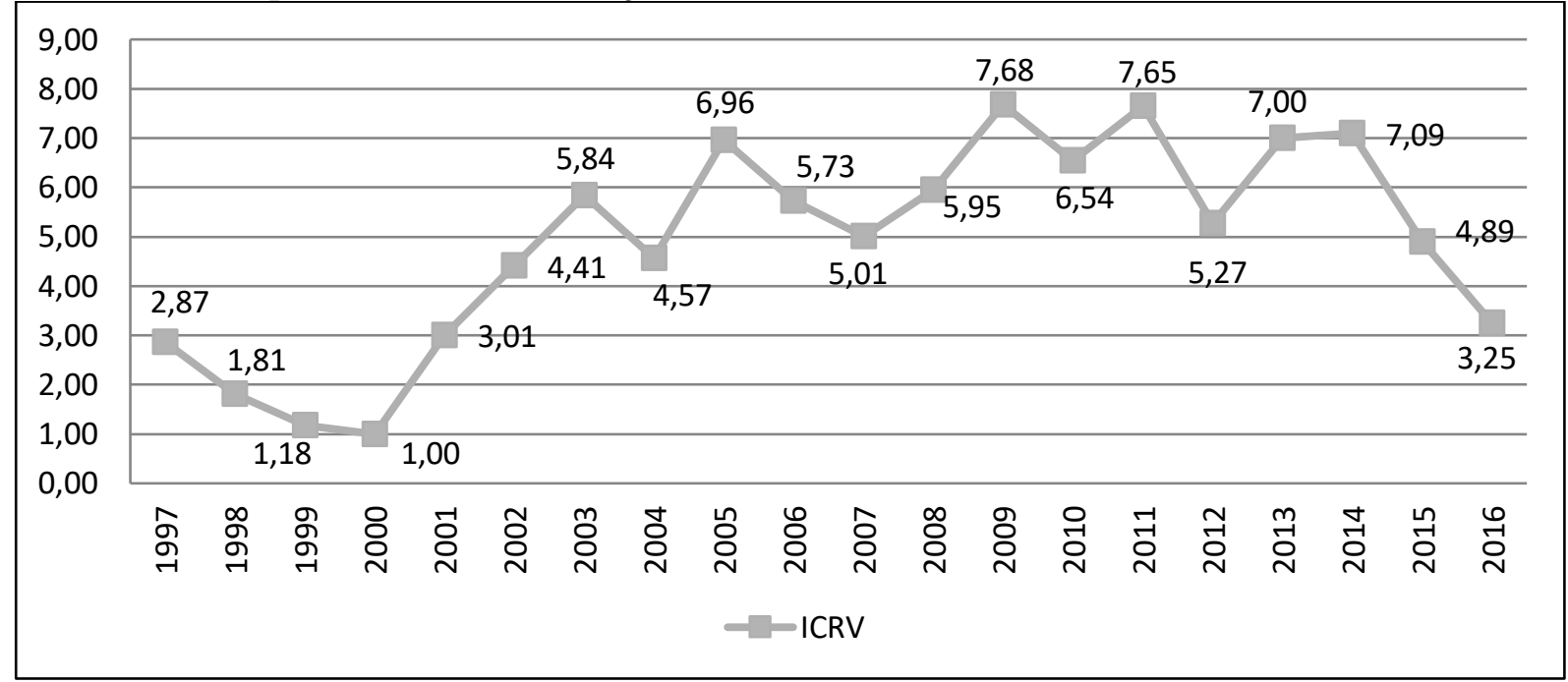

Fonte: Elaborado pelos autores a partir de dados da SECEX/ MDIC, 2017.

O ICRV é nitidamente crescente no período analisado, porém, com queda nos dois últimos anos da série, assim como no IVRE. Observa-se um ponto de inflexão na virada da década, anos 2000. A partir de então registram-se resultados crescentes, mesmo em períodos de crises a nível mundial, como 2008 e 2009. Entende-se que a vantagem nas exportações decorre da elevação da competitividade do setor. Comparando-se o primeiro e o último ano da série, tem-se um aumento de 0,38 pontos percentuais, aumento este que é inferior ao observado no IVRE, porém, que assegura competitividade ao setor de veículos aéreos paulista.

O gráfico 6 apresenta o IOR das exportações de aeronaves de São Paulo para o bloco econômico da União Europeia (1997 a 2016). Observa-se que os índices plotados no gráfico oscilam bastante, sem seguir uma tendência de longo prazo.

Gráfico 6: IOR das exportações de aeronaves paulistas para a União Europeia, 1997-2016.

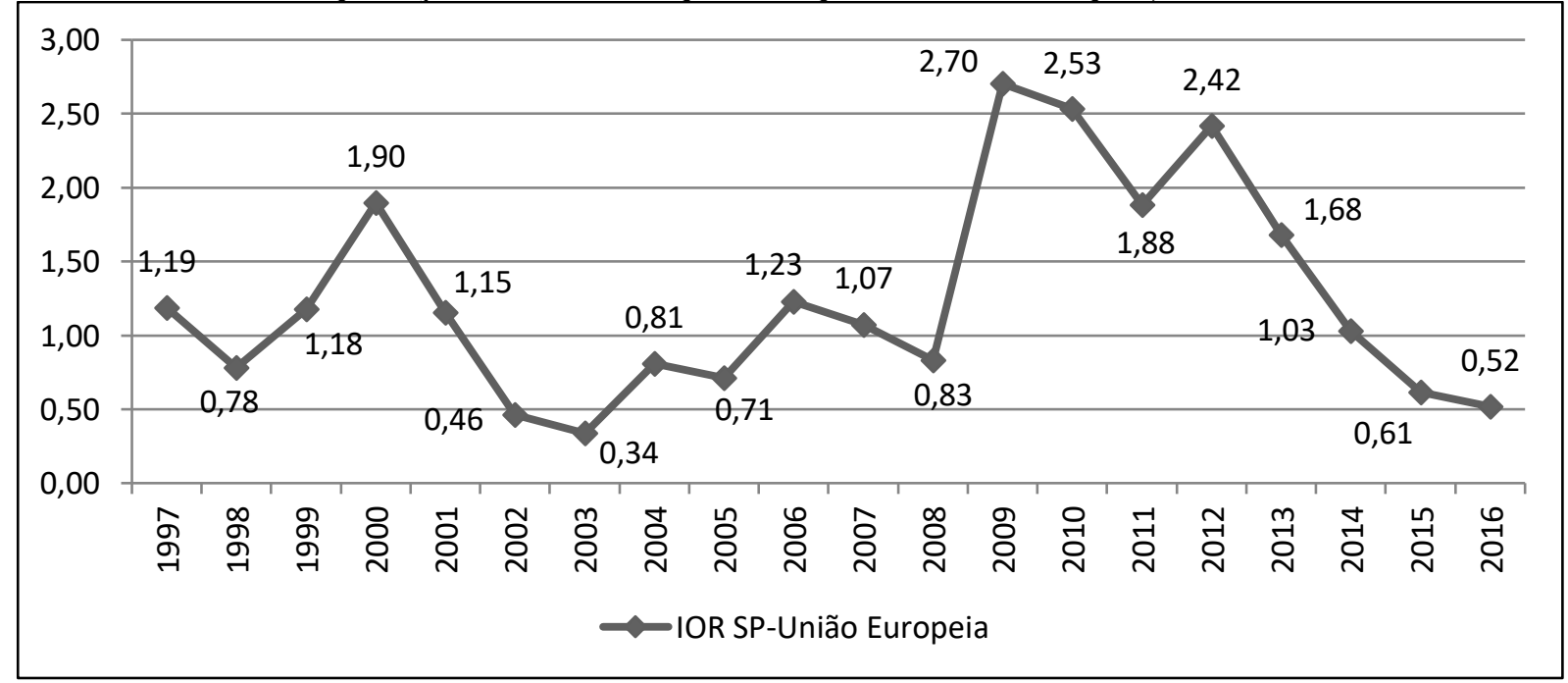


Fonte: Elaborado pelos autores a partir de dados do SECEX/ MDIC, 2017.

Constata-se que o comércio entre São Paulo e a União Europeia no setor de aeronaves é sempre positivo, porém, com picos esporádicos. Esboçou-se de 2003 a 2012 uma tendência ao crescimento do IOR, porém, este inverte a tendência a partir de 2013, quando apresenta constantes quedas, encerrando a série com IOR menor do que o inicial em 0,67 pontos percentuais. Nesse período recente a Europa enfrentou inúmeras turbulências que podem ter impactado no seu mercado de aeronaves e consequentemente na demanda. Podem-se enumerar alguns: problemas econômicos, como os calotes da dívida da Grécia; problemas políticos, como a saída do Reino Unido da UE; problema com terrorismo, com constantes ataques a aeronaves. Todos esses, podem ter influenciado em alguma medida à redução do IOR observado.

\subsection{Taxa de câmbio e comércio de veículos aéreos paulista: Teste de Cointegração de Johansen e o Teste de Causalidade de Granger}

Aplicada à segunda parte da metodologia, chega-se aos resultados apresentados nas tabelas $3,4,5$ e 6 . A tabela 3 mostra o teste $\mathrm{ADF}$ de raiz unitária para as séries em nível, primeiro requisito para determinar o método a ser utilizado.

Tabela 3: Teste ADF para as séries em nível: 1997.1 - 2016.12.

\begin{tabular}{lccr}
\hline \multicolumn{1}{c}{ Modelo } & $\begin{array}{c}\text { Taxa de câmbio real efetiva } \\
\text { (TXCAMBIO) }\end{array}$ & $\begin{array}{c}\text { Exportações de veículos } \\
\text { (EXPORT) }\end{array}$ & Valor crítico* \\
\hline Completo & $-2,590886$ & $-1,904935$ & $-3,42$ \\
Sem tendência & $-1,532608$ & $-2,354028$ & $-2,87$ \\
Sem tendência e sem constante & $-0,676415$ & 0,580249 & $-1,94$ \\
\hline
\end{tabular}

Fonte: Elaborado pelo autor a partir de dados do IPEADATA, 2017.

(*) Valor crítico de Dickey-Fuller a 5\%.

Os resultados mostram que ambas as variáveis testadas tiveram suas hipóteses nulas aceitas, ou seja, ao nível de 5\%, para os três modelos distintos, as séries de TXCAMBIO e EXPORT são não estacionárias. A partir desse resultado, testa-se a estacionariedade das séries em primeira diferença, utilizando também o teste ADF. Os resultados são apresentados na tabela 4.

Tabela 4: Teste ADF para as séries em primeira diferença: 1997.1 - 2016.12.

\begin{tabular}{lccc}
\multicolumn{1}{c}{ Modelo } & $\begin{array}{c}\text { Taxa de câmbio real efetiva } \\
\text { (TXCAMBIO) }\end{array}$ & $\begin{array}{c}\text { Exportações de veículos } \\
\text { (EXPORT) }\end{array}$ & Valor crítico* \\
\hline Completo & $-10,97454$ & $-13,08633$ & $-3,42$ \\
Sem tendência & $-10,98934$ & $-12,9704$ & $-2,87$ \\
Sem tendência e sem constante & $-11,00484$ & $-12,86489$ & $-1,94$ \\
\hline
\end{tabular}

Fonte: Elaborado pelo autor a partir de dados do IPEADATA, 2017.

(*) Valor crítico de Dickey-Fuller a 5\%.

Os resultados encontrados em primeira diferença, para ambas as séries, são de rejeição da hipótese nula. Logo, as séries são estacionárias em primeira diferença, e, portanto, são integradas de ordem 1. Observa-se que esse resultado também foi encontrado por Coelho e Recupero (2015), ao testarem a estacionariedade para a taxa de câmbio real efetiva e as exportações de automóveis do Brasil. Identificado que as séries em nível são não estacionárias, pode-se realizar o teste de cointegração de Johansen.

Porém, antes da realização do teste, é necessário identificar o número ideal de defasagens a serem utilizadas. Para tanto, recorreu-se ao critério de seleção de Schwartz, que 
indicou a utilização de 3 defasagens. A tabela 5 apresenta os resultados do teste de cointegração de Johansen para o período de 1997 a 2016.

Tabela 5: Testes de cointegração de Johansen: 1997.1 - 2016.12.

\begin{tabular}{ccccc}
\hline $\mathbf{H}_{\mathbf{0}}$ : rank=p & Teste do Traço & Valor crítico (5\%) & Teste do Máximo Autovalor & Valor crítico (5\%) \\
\hline $\mathrm{P}=0$ & 32,63745 & 15,49471 & 30,3318 & 14,2646 \\
$\mathrm{P} \leq 1$ & 2,305646 & 3,841466 & 2,305646 & 3,841466 \\
\hline
\end{tabular}

Fonte: Elaborado pelo autor a partir de dados do IPEADATA, 2017.

Os resultados do teste do traço e do teste do máximo autovalor mostram que não existe cointegração entre a taxa de câmbio real efetiva e as exportações de veículos aéreos no período de 1997 a 2016, o que implica dizer que não existe relação entre as variáveis no longo prazo, assim como os resultados de Coelho e Recupero (2015) para o caso das exportações de automóveis de 1990 a 2005.

De forma a confirmar os resultados, utilizou-se o teste de causalidade de Granger (1969) para o mesmo período. Devido a não-estacionariedade das variáveis em nível, apresentadas na tabela 3, esse teste foi realizado com as variáveis em primeira diferença, pois como explica Coelho e Recupero $(2015$, p. 47) "o teste de causalidade nas variáveis em nível não terá um resultado estatisticamente correto, pois a estatística do teste não converge para uma distribuição F". Os resultados são apresentados na tabela 6 .

Tabela 6: Teste de causalidade de Granger: 1997.1 - 2016.12.

\begin{tabular}{cccc}
\hline Ho - Hipótese nula & Teste $\mathbf{F}$ & Probabilidade & Resultado \\
\hline DTXCAMBIO não causa DEXPORT & 0,05727 & 0,9820 & Não rejeitado \\
DEXPORT não causa DTXCAMBIO & 1,49445 & 0,2168 & Não rejeitado \\
\hline
\end{tabular}

Fonte: Elaborado pelo autor a partir de dados do IPEADATA, 2017.

Os resultados indicam que não existe causalidade no sentido de Granger entre as variáveis taxa de câmbio real efetiva e exportações de veículos aéreos em primeira diferença. Isso indica, conforme a probabilidade, que a taxa de câmbio não precede as exportações de veículos leves, o que não confirma a hipótese levantada pela literatura para este caso.

\section{Considerações finais}

O objetivo deste artigo foi investigar o desempenho do setor de veículos aéreos de São Paulo de 1997 a 2016. Os resultados do trabalho indicam que o setor conseguiu se estabelecer no mercado mundial com vantagens nas trocas e com competitividade, estando uma de suas empresas, a Embraer, entre as quatro maiores fabricantes do mundo, e sendo a atual líder do setor de aeronaves regionais.

Observa-se no período em análise, 1997 a 2016, crescimento tanto no IVRE quanto no ICRV, com importante ponto de inflexão no ano 2000, para ambos indicadores. Esses resultados alcançados pelo setor só foi possível graças às políticas estruturais gradativas e que abrangeram desde estrutura física, passando por centro de pesquisa e desenvolvimento (P\&D) até subsídios para se estabelecer de forma competitiva. Políticas que perpassaram diversos governos.

Diferentemente dos índices IVRE e ICRV, o IOR não apresentou tendência de crescimento no longo prazo. Com grandes oscilações durante todo o período, tem-se que a relação comercial entre o Estado de São Paulo e a União Europeia está decrescendo nos últimos anos, especialmente a partir de 2013, o que pode estar ocorrendo em decorrência de 
inúmeros fatores, mas que demanda uma preocupação no sentido de buscar novos mercados para suprir essa lacuna criada.

A partir dos testes de cointegração de Johansen e de causalidade de Granger, foi possível verificar se as exportações de veículos aéreos de São Paulo possuem relação com a taxa de câmbio real efetiva no período de 1997 a 2016. Os resultados dos testes mostraram que não há. Esse resultado vai contra a literatura corrente, que aponta o câmbio como um dos principais determinantes da quantidade exportada. Esse resultado pode ter sido consequência do formato de compra e venda do setor, que é, em grande parte, via contratos de médio prazo, que não sofreriam impactos da taxa de câmbio.

Para pesquisas futuras é interessante acompanhar o desempenho do setor em anos posteriores, para que se possa observar como este irá se comportar diante das adversidades provocadas pelas turbulências políticas e econômicas pelas quais passa o mundo atualmente. Além de verificar, a partir de outras metodologias, é possível verificar se as vantagens nas exportações e competitividade são mantidas, como se observou durante as turbulências de 2001 e 2008, ou se será mais prejudicada, chegando a apresentar queda. Outro exercício pertinente é fazer a quebra dos períodos e realizar a análise da relação com a taxa de câmbio.

\section{Referências bibliográficas}

BALASSA, B. Trade liberalization and revealed comparative advantage. The Manchester School of Economic and Social Studies, [S. 1.], n. 33, May 1965.

BASTOS, C. E. Atributos de Parcerias de Sucesso em Cadeias de Suprimentos: um estudo de caso na relação fabricante-fornecedor na indústria aeronáutica. Dissertação (Mestrado). Universidade de São Paulo (USP). 2006.

BERNARDES, R.; PINHO, M. S.. Aglomeração e Aprendizado na Rede de Fornecedores da Embraer. São Paulo: RedeSist, 2002.

BRASIL. Ministério de Desenvolvimento, Indústria e Comércio. ALICE-Web- Sistema de Análise das Informações de Comércio Exterior. Brasília, DF: MDIC, 2015. Disponível em: <http://aliceweb2.mdic.gov.br/>. Acesso em: 05 jan. 2015.

COELHO, Alexandre Bragança; RECUPERO, Leonardo. TAXA DE CÂMBIO REAL EFETIVA E EXPORTAÇÕ̃ES DE AUTOMÓVEIS NO BRASIL, 1990-2005. Revista de Economia e Agronegócio-REA, v. 6, n. 1, 2015.

CORONEL, D. A. et al. Exportações do complexo brasileiro de soja: Vantagens comparativas reveladas e orientação regional. v. 17, n. 4, 2008.

CUSHMAN, David O.; DE VITA, Glauco. Exchange rate regimes and FDI in developing countries: A propensity score matching approach. Journal of International Money and Finance, v. 77, p. 143-163, 2017.

DICKEY, D. A., FULLER, W. A. Distribution of the estimators for autoregressive time series with a unit root. Journal of American Statistical Association, 74, 427-431, 1979.

FORJAZ, M. C. S. As Origens da Embraer. Tempo Social: Revista de sociologia da USP, v.17, n.1, pp. 281-298. Junho de 2005. 
GHINATO, P.. Sistema Toyota de Produção: Mais do que Simplesmente Just-In-Time. Caxias do Sul: Editora da Universidade de Caxias do Sul - EDUCS, v. 1. 200p., 1996.

GRANGER, C.W.J. Investigating causal relationships by econometric models and cross spectral methods. Econometrica, v 37, p. 424-438, 1969.

JOHANSEN, S. Statistical analysis of cointegration vectors. Journal of Economic Dynamics and Control, Vol.12, p. 231-254, 1988.

KALECKI, M. Teoria da Dinâmica Econômica. Coleção Os Economistas. São Paulo; Abril Cultural, 1983.

MANINI, Ricardo; CALDAS, Graça. Céu azul: comunicação para inspirar o comportamento econômico e inovar a Embraer. Comunicação \& Inovação, v. 18, n. 38, p. 46-61, 2017.

MOLLO, Maria de Lourdes Rollemberg; SILVA, Maria Luiza Falcão. A liberalização do câmbio no Brasil: revisitando a discussão dos pressupostos teóricos embutidos nas prescrições cambiais alternativas. Estudos Econômicos (São Paulo), v. 29, n. 2, p. 189-227, 2016.

MORAIS, Isabela Carolina Barbosa et al. A inserção de empresas brasileiras no mercado chinês: o caso Embraer. Fronteira: revista de iniciação científica em Relações Internacionais, v. 15, n. 29 e 30, p. 165-181, 2016.

SCHUMPETER, J. A. Teoria do Desenvolvimento Econômico. Coleção Os Economistas. São Paulo; Abril Cultural, 1982.

SILVA, F. A. et al. Competitividade das exportações brasileiras de mamão, 1995 a 2008. Revista de Economia e Agronegócio - REA. v. 9, n. 3, 2015.

VOLLRATH, T. L. Competitiveness and protection in world agriculture. Agriculture Information Bulletin, [S.1], n. 567, USDA, July, 1989.

YEATS, A. Does Mercosur's trade performance raise concerns about the effects of regional trade arrangements? Policy, Planning and Research Working Paper No. 1729, Washington: Banco Mundial, fev. 1997. 